(2) Open Access Full Text Article

\title{
Anorexia nervosa depends on adrenal sympathetic hyperactivity: opposite neuroautonomic profile of hyperinsulinism syndrome
}

\author{
This article was published in the following Dove Press journal: \\ Diabetes, Metabolic Syndrome and Obesity:Targets and Therapy \\ 8 September 2010 \\ Number of times this article has been viewed
}

\author{
Fuad Lechin ${ }^{1,2}$ \\ Bertha van der Dijs ${ }^{1,2}$ \\ Betty Pardey-Maldonado' \\ Jairo E Riveral \\ Scarlet Baez' \\ Marcel E Lechin ${ }^{3}$ \\ 'Department of Pathophysiology, \\ Sections of Neuroendocrinology, \\ Neuropharmacology, and \\ Neurochemistry, Instituto de Medicina \\ Experimental, Faculty of Medicine, \\ Universidad Central de Venezuela, \\ Caracas; ${ }^{2}$ Instituto de Vias Digestivas \\ Caracas, Centro Clínico Profesional, \\ Caracas, Venezuela; ${ }^{3}$ Department of \\ Internal Medicine, Texas A and $M$ \\ Health Science Center, College of \\ Medicine, Texas, USA
}

Objective: The aim of our study was to determine the central and peripheral autonomic nervous system profiles underlying anorexia nervosa (AN) syndrome, given that affected patients present with the opposite clinical profile to that seen in the hyperinsulinism syndrome.

Design: We measured blood pressure and heart rate, as well as circulating neurotransmitters (noradrenaline, adrenaline, dopamine, plasma serotonin, and platelet serotonin), using highperformance liquid chromatography with electrochemical detection, during supine resting, one minute of orthostasis, and after five minutes of exercise. In total, $22 \mathrm{AN}$ patients (12 binge-eating/ purging type and 10 restricting type) and age-, gender-, and race-matched controls ( $70 \pm 10.1 \%$ versus $98 \pm 3.0 \%$ of ideal body weight) were recruited.

Results: We found that patients with AN had adrenal sympathetic overactivity and neural sympathetic underactivity, demonstrated by a predominance of circulating adrenaline over noradrenaline levels, not only during the supine resting state ( $52 \pm 2$ versus $29 \pm 1 \mathrm{pg} / \mathrm{mL}$ ) but also during orthostasis $(67 \pm 3$ versus $32 \pm 2 \mathrm{pg} / \mathrm{mL}, P<0.05)$ and after exercise challenge (84 \pm 4 versus $30 \pm 3 \mathrm{pg} / \mathrm{mL}, P<0.01)$.

Conclusion: Considering that this peripheral autonomic nervous system disorder depends on the absolute predominance of adrenomedullary $\mathrm{C} 1$ adrenergic nuclei over A5 noradrenergic pontine nucleus, let us ratify the abovementioned findings. The AN syndrome depends on the predominance of overwhelming adrenal sympathetic activity over neural sympathetic activity. This combined central and autonomic nervous system profile contrasts with that registered in patients affected by hyperinsulinism, hypoglycemia, and bulimia syndrome which depends on the absolute predominance of neural sympathetic activity.

Keywords: anorexia nervosa, adrenal sympathetic activity, adrenaline, noradrenaline, eating disorders

\section{Introduction}

Anorexia nervosa (AN) is a disorder of unknown etiology characterized by restricting eating and a relentless pursuit of thinness. There is a narrow range of age of onset (early adolescence), stereotypic presentation of symptoms and course, and relative gender specificity. Patients with AN and bulimia have a number of endocrine abnormalities which can be interpreted as adaptations to starvation. ${ }^{1,2}$

Individuals with AN have an ego-syntonic resistance to eating and a powerful pursuit of weight loss, yet are paradoxically preoccupied with food and eating rituals to the point of obsession. Individuals have a distorted body image and, even when emaciated,

\footnotetext{
Correspondence: Fuad Lechin Apartado 80 983, Caracas 1080-A, Venezuela

Tel +58 2I $296 \mathrm{I} 1048$

$\mathrm{Fax}+582129610172$

Email flechin@telcel.net.ve
} 
tend to see themselves as "fat", express denial of being, and compulsively exercise to excess. They are often resistant to treatment, and lack insight regarding the seriousness of the medical consequences of their disorder. In addition to the above, the relative contributions of psychologic and/or physiologic factors to the appearance and development of the clinical symptoms included into the diagnostic criteria according to the Diagnostic and Statistical Manual of Mental Disorders, 4th Edition (DSM-IV) are not well defined. These criteria include two types of AN, ie, the restricting type, in which the person is not regularly engaged in binge-eating or pursuing behavior, and the binge-eating/purging type. Furthermore, individuals with AN display motor restlessness. We investigated the autonomic nervous system and circulating neurotransmitters of 22 patients ( 12 binge-eating/purging type and 10 restricting type) referred to our institute for assessment, in an effort to find possible neuropharmacologic therapeutic strategies for this disease.

\section{Methods}

The study was conducted in accordance with the guidelines of the Declaration of Helsinki. Written informed consent was obtained after the purpose, nature, and potential risks had been explained to the subjects. The experimental protocol was approved by the ethical committee of the Fundación Instituto Medicina Experimental.

\section{Patients}

The study included 22 female AN patients (10 restricted type and 12 binge-eating type) and a group of age-, gender-, and race-matched controls. The diagnoses were made according to DSM-IV criteria. Mean age \pm standard deviation (SD) of the AN patients was $22 \pm 6.4$ years and weight $70 \pm 10.1 \%$ of ideal body weight, according to Metropolitan Life Insurance Company tables. All patients and controls were extensively evaluated (physically, endoscopically, radiologically, biochemically, bacteriologically, and immunologically) in order to rule out any other physical illness. Exclusion criteria included pregnancy, lactation, smoking, and alcohol abuse. Neither patients nor controls took any medication for 15 days prior to the beginning of the study.

Measurement of blood pressure (BP) and heart rate (HR) as well as drawing of blood samples were performed simultaneously. Supine BP measurements were taken in a standardized fashion using appropriate-sized cuffs and a random-zero mercury sphygmomanometer. All measurements were taken in accordance with a previously published protocol. ${ }^{3}$
Blood samples for plasma neurotransmitter determinations were obtained simultaneously with BP and HR measurements through a heparinized catheter, inserted into the antebrachial contralateral vein 15 minutes before the first BP and HR measurements. Plasma noradrenaline, adrenaline, dopamine, free serotonin (f5-HT) and platelet serotonin (p5-HT) levels were measured during supine rest, one minute of orthostasis, and after five minutes of moderate exercise. ${ }^{3}$ All tests were performed on subjects after 10 hours of fasting. A physician in constant attendance noted any symptoms reported by the subjects.

\section{Analytic methods}

Noradrenaline, adrenaline, dopamine, plasma f5-HT, and p5-HT levels were measured. For all parameters, the samples were assayed in duplicate and all determinations were made simultaneously. We used reverse-phase, ion-pair high performance liquid chromatography with electrochemical detection for the measurement of monoamines. Optimization of chromatographic conditions and attainment of adequate quantification parameters allowed us to maximize sensitivity and reproducibility.

Blood for catecholamine and serotonin assays was transferred to plastic tubes, each containing $20 \mathrm{mg}$ of ethylenediaminetetraacetic acid (EDTA) and $10 \mathrm{mg}$ of sodium bisulphite/mL in solution. The tubes were carefully inverted and placed on ice. The blood was promptly centrifuged at $600 \mathrm{rpm}$ for 15 minutes at $4^{\circ} \mathrm{C}$ in order to obtain platelet-rich plasma. Two milliliters of platelet-rich plasma, obtained for determination of $\mathrm{p} 5$-HT, were taken and stored at $-70^{\circ} \mathrm{C}$ until assayed. The remaining blood was again centrifuged at $7000 \mathrm{rpm}$. The supernatant, platelet-poor plasma, was divided into two portions for determination of catecholamines and f5-HT, after which the portions were stored at $-70^{\circ} \mathrm{C}$ until assayed.

\section{Reagents and standards}

Noradrenaline, adrenaline, dopamine, serotonin creatinine sulfate, dihydroxybenzylamine, sodium octyl sulfate, dibutylamine, acid-washed aluminum oxide, $\mathrm{KH}_{2} \mathrm{PO}_{4}$, citric acid, and EDTA were purchased from Sigma-Aldrich (St Louis, MO). Microfilters were purchased from Whatman Inc. (Florham Park, NY) through Merck SA, (Caracas, Venezuela). Acetonitrile and 2-propanol were obtained from Merck SA. Glass-distilled water was deionized and filtered through a Millipore Milli-Q reagent grade water system (Bedford, MA). Solvents were filtered through a $0.2 \mu \mathrm{m}$ Millipore filter and were vacuum de-aerated. Standard 
solutions $(1 \mathrm{mmo} / \mathrm{L})$ were prepared in $0.1 \mathrm{~mol} / \mathrm{L}$ perchloric acid and diluted to the desired concentration.

\section{Equipment}

Liquid chromatography was performed using a Waters 515 HPLC pump (Waters Milford, MA) equipped with a Rheodyne valve injector $7125 \mathrm{i}$, which was fitted with a $50 \mu \mathrm{L}$ sample loop (Rheodyne; Berodine, Berkeley, CA). A $15 \mathrm{~cm} \times 4.6 \mathrm{~mm}$ inner diameter Discovery C18 column packed with octadecyl silane $5 \mu \mathrm{m}$ particles was preceded by a column prefilter of $2 \mu \mathrm{m}$ porosity, both from Supelco/Sigma-Aldrich. The detection system was a 460 electrochemical detector (Waters Corporation, Milford, MA). The potential of the glass carbon working electrode was set at $\pm 0.61 \mathrm{~V}$ versus the silver-silver chloride $(\mathrm{Ag}-\mathrm{AgCl})$ reference electrode for detection of catecholamines and $0.70 \mathrm{~V}$ versus the $\mathrm{Ag}-\mathrm{AgCl}$ for detection of indolamines. The chromatograms were registered and quantified using Empower software from Waters Corporation. The results were corrected for the volume of EDTA added.

\section{Analytical assays}

\section{Plasma catecholamines}

The assay was performed by extraction of the catecholamines onto $20 \mathrm{mg}$ of alumina followed by elution with $200 \mu \mathrm{L}$ of $1.0 \mathrm{~mol} / \mathrm{L} \mathrm{HClO}_{4}$ using regenerated cellulose microfilters of $0.2 \mu \mathrm{m}$ pore size purchased from Whatman Inc. We calibrated the instrument with standard plasma; after incubation with acid-washed aluminum oxide, a plasma pool of free catecholamines was processed similarly to the plasma samples, but $20 \mu \mathrm{L}$ of a standard solution of noradrenaline, adrenaline, and dopamine $(50,25$, and $25 \mathrm{ng} / \mathrm{mL}$, respectively) was added to the plasma pool. Both the standard plasma and the sample plasma were supplemented with $20 \mu \mathrm{L}$ of internal standard (100 ng/mL of dihydroxybenzylamine). The mobile phase was $\mathrm{KH}_{2} \mathrm{PO}_{4} 6.8045 \mathrm{~g} / \mathrm{L}$, EDTA $0.1 \mathrm{~g} / \mathrm{L}$, and di-Nbutylamine $100 \mu \mathrm{l} / \mathrm{L}$. Sodium octyl sulphate was added as an ion-pair agent at a concentration of $0.6125 \mathrm{~g} / \mathrm{L}$, with the $\mathrm{pH}$ adjusted to 5.6 . The flow rate was $0.4 \mathrm{~mL} / \mathrm{min}$. The sensitivities of this method for noradrenaline, adrenaline, and dopamine, respectively, were $6.4,5.8$, and $2.0 \mathrm{pg} / \mathrm{mL}$. The intra-assay coefficients of variation were $2.8,4.0$, and $4.0 \%$, respectively. The interassay coefficients of variation were $6.7,4.5$, and $4.3 \%$, respectively.

\section{Plasma indolamines}

After sonication of platelet-rich plasma to disrupt the platelets (Ultrasonic Liquid Processor, Model 385; Heat Systems Ultrasonics Inc., Farmingdale, NY), both platelet-rich and platelet-poor plasma were processed in the same way, ie, $200 \mu \mathrm{L}$ of $3.4 \mathrm{~mol} / \mathrm{L}$ perchloric acid and $50 \mu \mathrm{L}$ of 5 -hydroxytryptophan solution $(114.5 \mu \mathrm{g} / \mathrm{mL})$ as internal standard, were added to $1 \mathrm{~mL}$ of plasma vortexed and centrifuged at $10,000 \mathrm{rpm}$ for 15 minutes at $4^{\circ} \mathrm{C}$. The supernatant was filtered through a $0.22 \mu \mathrm{m}$ membrane (Millipore) and $10 \mu \mathrm{L}$ was injected into the column. Calibration runs were generated by spiking blank platelet-poor plasma with $50 \mu \mathrm{L}$ of a solution containing 5-HT $(10 \mu \mathrm{g} / \mathrm{mL})$ and $50 \mu \mathrm{L}$ of 5 -hydroxytryptophan $(114.5 \mu \mathrm{g} / \mathrm{mL})$. This standard plasma was processed in the same manner as the samples. The mobile phase was citric acid $3.8424 \mathrm{~g} / \mathrm{L}$, sodium acetate $4.1015 \mathrm{~g} / \mathrm{L}$, EDTA $0.100 \mathrm{~g} / \mathrm{L}$, di-N-butylamine $100 \mu \mathrm{l} / \mathrm{L}$, and $30 \mathrm{ml} / \mathrm{L}$ of 2-propanol. Sodium octyl sulphate was added as an ion-pair agent in a concentration of $4.25 \mathrm{mg} / \mathrm{L}$ with a $\mathrm{pH}$ of 5.0 . The flow rate was $0.610 \mathrm{~mL} / \mathrm{min}$. The sensitivity of the method for serotonin was $0.1 \mathrm{ng} / \mathrm{mL}$. The intra-assay coefficients of variation for $\mathrm{p} 5$-HT and f5-HT were 6.2 and $8.7 \%$, respectively.

\section{Statistical methods}

Results are presented as the mean \pm standard error of measurement (SEM). Multivariate one-way analysis of variance (ANOVA) with repeated measurements, and correlation coefficients (exploratory factor analysis) were used. Dbase Stats (TM) by Ashton Tate and Statview SE \pm Graphics by Abacus were used for the statistical analysis.

\section{Results}

We did not find any significant differences between the two clinical types of AN in our patients.

\section{Cardiovascular parameters}

Neither systolic BP nor diastolic BP showed significant variations during orthostasis or after moderate exercise in any group. However, differential pressure showed a significant increase during orthostasis in the AN group. HR showed significant and progressive rises during both orthostasis and exercise periods in the AN group but not in controls (Table 1).

\section{Catecholamines}

Plasma noradrenaline showed significant and progressive increases during orthostasis and exercise in the two groups. However, the noradrenaline values and their increases were significantly higher in controls than in the AN patients. In addition, adrenaline showed important and significant increases during orthostasis and exercise in the AN patients, but not in controls. Plasma dopamine levels showed a 
Table I Systolic blood pressure, diastolic blood pressure, heart rate, noradrenaline, adrenaline, dopamine, platelet-serotonin, and free serotonin blood values, at 0' (resting), I' (orthostasis) and 5' (post-exercise) in 22 patients with anorexia nervosa and their controls

\begin{tabular}{|c|c|c|c|c|c|c|c|}
\hline & & \multirow[t]{2}{*}{0 minutes } & \multirow[t]{2}{*}{ I minutes } & \multirow[t]{2}{*}{5 minutes } & \multicolumn{3}{|l|}{$P$ values } \\
\hline & & & & & 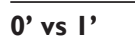 & $0^{\prime}$ vs 5' & I'vs 5 ' \\
\hline \multirow[t]{2}{*}{ SBP } & $-A N$ & $152 \pm 5$ & $158 \pm 3$ & $171 \pm 6$ & $<0.05^{*}$ & $<0.02 *$ & $<0.02 *$ \\
\hline & $-C$ & $123 \pm 5$ & $124 \pm 6$ & $123 \pm 2$ & n.s. & n.s. & n.s. \\
\hline \multirow[t]{2}{*}{ DBP } & $-\mathrm{AN}$ & $60 \pm 3$ & $60 \pm 2$ & $61 \pm 3$ & n.s. & n.s. & n.s. \\
\hline & $-C$ & $80 \pm 4$ & $77 \pm 1$ & $75 \pm 3$ & n.s. & n.s. & n.s. \\
\hline \multirow[t]{2}{*}{ HR } & $-\mathrm{AN}$ & $71 \pm 3$ & $79 \pm 4$ & $83 \pm 6$ & $<0.02 * *$ & $<0.0 I^{* * *}$ & $<0.00 I^{* *}$ \\
\hline & $-C$ & $66 \pm 2$ & $67 \pm 2$ & $70 \pm 4$ & n.s. & n.s. & n.s. \\
\hline \multirow[t]{2}{*}{ NA } & $-\mathrm{AN}$ & $166 \pm 4$ & $169 \pm 5$ & $175 \pm 5$ & n.s. & n.s. & n.s. \\
\hline & $-C$ & $178 \pm 2$ & $202 \pm 4$ & $223 \pm 5$ & $<0.05^{*}$ & $<0.0 \mathrm{I}^{* *}$ & $<0.01 * *$ \\
\hline \multirow[t]{2}{*}{$A D$} & $-\mathrm{AN}$ & $52 \pm 2$ & $67 \pm 3$ & $84 \pm 4$ & $<05^{*}$ & $<0.00 I^{* * * *}$ & $<0.00 I^{* * * *}$ \\
\hline & $-C$ & $29 \pm 1$ & $32 \pm 2$ & $30 \pm 2$ & n.s. & n.s. & n.s. \\
\hline \multirow[t]{2}{*}{ DA } & $-\mathrm{AN}$ & $18 \pm 1$ & $21 \pm 2$ & $23 \pm 2$ & n.s. & n.s. & $<0.05^{*}$ \\
\hline & $-C$ & $17 \pm 2$ & $18 \pm 2$ & $19 \pm 3$ & n.s. & n.s. & n.s. \\
\hline \multirow[t]{2}{*}{ p5-HT } & $-\mathrm{AN}$ & $228 \pm 19$ & $249 \pm 22$ & $225 \pm 25$ & n.s. & n.s. & n.s. \\
\hline & $-C$ & $282 \pm 21$ & $292 \pm 25$ & $276 \pm 30$ & n.s. & n.s. & n.s. \\
\hline \multirow[t]{2}{*}{ f5-HT } & $-\mathrm{AN}$ & $3.2 \pm 1$ & $13.7 \pm 1$ & $24.5 \pm 2$ & $<0.00 I^{* * *}$ & $<0.00 I^{* * *}$ & $<0.00 I^{* * *}$ \\
\hline & $-C$ & $2.99 \pm 1$ & $1.8 \pm 1$ & $3.3 \pm 1$ & n.s. & n.s. & n.s. \\
\hline
\end{tabular}

Notes: Results are expressed as mean \pm SEM. $* P<0.05$; $* * P<0.02$, $* * * P<0.001$. Most decimals were omitted.

Abbreviations: $\mathrm{AD}$, adrenaline (in $\mathrm{pg} / \mathrm{mL}$ ); $\mathrm{AN}$, anorexia nervosa; $\mathrm{C}$, controls; $\mathrm{DA}$, dopamine (in $\mathrm{pg} / \mathrm{mL}$ ); SBP, systolic blood pressure (in mmHg); $\mathrm{DBP}$, diastolic blood pressure (in $\mathrm{mmHg}$ ); HR, heart rate (in beats/minute) $\mathrm{p} 5-\mathrm{HT}$, platelet serotonin (in $\mathrm{ng} / \mathrm{mL}$ ); f5-HT, free serotonin (in $\mathrm{ng} / \mathrm{mL}$ ); $\mathrm{NA}$, noradrenaline ( $\mathrm{pg} / \mathrm{mL}$ ); $\mathrm{n.s.}$, non significant; SEM, standard error of measurement.

significant increase during orthostasis in AN patients but not in controls.

\section{Indolamines}

p5-HT did not show any significant variation in any group. Plasma f5-HT, (ie, outside the platelets) showed mean basal values which were greater in AN patients than in controls and showed progressive and significant increases during orthostasis and exercise in AN patients but not in controls. Significant correlations amongst the different physiologic and neurochemical variables during rest, orthostasis, and after moderate exercise are shown in Table 2.

\section{Discussion}

The results presented in this study demonstrate that AN patients have adrenal sympathetic overactivity, as shown by the low noradrenaline:adrenaline plasma ratio registered during orthostasis and exercise testing. ${ }^{4}$ The fact that falls in the noradrenaline:adrenaline ratio were opposed by systolic BP and HR rises fits well with the hypothesis that the basal adrenal sympathetic overactivity which underlies this syndrome was accentuated throughout the stress challenge. This adrenal sympathetic hyperactivity is responsible for the f5-HT rises also registered in these patients, and should be attributed to the increase in adrenaline plasma levels which provokes platelet aggregation, ${ }^{5}$ as revealed by the close positive correlation between adrenaline and f5-HT levels seen in this study. In addition, we did not find significant physiologic or neuroautonomic differences between the two types of AN patients.

Table 2 Significant correlations ( $r$ ) for physiologic and plasma neurotransmitter parameters at 0 minutes (resting), one minute (orthostasis), and five minutes (post-exercise) in 22 anorexia nervosa patients and their controls

\begin{tabular}{|c|c|c|c|c|c|c|c|c|}
\hline & SBP & DBP & HR & NA & $A D$ & DA & p5-HT & f5-HT \\
\hline \multicolumn{9}{|c|}{ AN $0 \mathrm{~min}$} \\
\hline $\mathrm{HR}$ & $0.6 I^{*}$ & & & & & & & \\
\hline$A D$ & $0.66^{*}$ & & $0.70^{*}$ & & & & & \\
\hline DA & & & & & $0.64^{*}$ & & & \\
\hline $\mathrm{f5}-\mathrm{HT}$ & & & $0.70 *$ & & $0.70^{*}$ & & & \\
\hline \multicolumn{9}{|c|}{$\mathrm{C} 0 \mathrm{~min}$} \\
\hline $\mathrm{HR}$ & $0.61 *$ & & & & & & & \\
\hline \multicolumn{9}{|c|}{ AN I min } \\
\hline HR & $0.60 *$ & & & & & & & \\
\hline$A D$ & $0.60 *$ & & $0.69 * *$ & & & & & \\
\hline DA & & & & & 0.63 ** & & & \\
\hline $\mathrm{f5}-\mathrm{HT}$ & & & $0.60 *$ & & $0.69 *$ & & & \\
\hline \multicolumn{9}{|c|}{ C I min } \\
\hline$A D$ & & & $0.60 *$ & & & & & \\
\hline \multicolumn{9}{|c|}{ AN 5 min } \\
\hline HR & $0.70 * *$ & & & & & & & \\
\hline$A D$ & $0.75^{* *}$ & & $0.80 * * * *$ & & & & & \\
\hline $\mathrm{f5}-\mathrm{HT}$ & & & $0.66^{*}$ & & $0.68^{*}$ & & & \\
\hline
\end{tabular}

Notes: $* P<0.05 ; * * P<0.02 ; * * * P<0.001$.

Abbreviations: SBP, systolic blood pressure; DBP, diastolic blood pressure; HR, heart rate; NA, noradrenaline; $A D$, adrenaline; $D A$, dopamine; $\mathrm{p} 5-\mathrm{HT}$, platelet serotonin; $\mathrm{f} 5-\mathrm{HT}$, free serotonin. 
These findings contrast with the enhancement of the noradrenaline:adrenaline ratio and diastolic BP rises registered in both controls and patients affected by hyperinsulinism syndrome. ${ }^{6,7}$ We have demonstrated that this syndrome is associated with maximal enhancement of neural sympathetic activity and hypoglycaemia. ${ }^{6-9}$ These phenomena depend on both central and peripheral autonomic nervous system mechanisms. The former depends on A5 noradrenergic axons which inhibit $\mathrm{C} 1$ adrenergic medullary neurons, whereas the latter should be attributed to the direct inhibitory effect of sympathetic nerves at the adrenal gland level. ${ }^{10-13}$

The above findings are reinforced by the demonstration that a small oral dose of clonidine (an alpha-2 agonist) is able to reverse peripheral (plasma) noradrenaline:adrenaline ratio enhancement. ${ }^{14}$ It should be borne in mind that although the adrenergic medullary nuclei may also be inhibited by clonidine, this effect is only registered in mammals with adrenal sympathetic overactivity (minimized noradrenaline:adrenaline plasma ratio). This effect can be attributed to the fact that although the drug is an alpha-2 agonist (preferentially), it also acts at imidazole receptors which crowd adrenal medullary neurons but not A5 neurons. ${ }^{15-22}$ These facts are reinforced by the observation that other imidazole agonists (rilmenidine, lofexidin) which do not act at the A5 neurons, display a powerful agonistic inhibitory effect at the medullary nuclei. ${ }^{18-26}$

Some additional information helps to understand the central and peripheral autonomic nervous system interactions which underlie the two opposite syndromes, ie, AN and hyperinsulinism. Oral glucose is absorbed at the small bowel and reaches the pancreatic beta cells which secrete insulin and send inhibitory drive (via gamma aminobutyric acid, GABA) to alpha cells. Plasma insulin crosses the blood-brain barrier and excites the A5 neurons, ${ }^{8,9}$ which send inhibitory axons to the adrenal medullary nuclei. ${ }^{10}$ Plasma glucagon also crosses the blood-brain barrier and excites the adrenal nuclei. ${ }^{27,28}$ At the peripheral level, sympathetic nerves which innervate alpha cells, but not beta cells, excite additional release of glucagon into the plasma. Finally, the A5 and the adrenal nuclei interchange inhibitory axons and, thus, predominance of A5 is responsible for neural sympathetic activity, hyperinsulinism, hypoglycemia, and bulimia, whereas overactivity of the other neuroendocrine circuitry results in adrenal sympathetic hyperactivity, hyperglucagonism, hyperglycemia, and anorexia. ${ }^{29,30}$

With respect to all the above, it should be noted that although the thoracic sympathetic nerves that innervate pancreatic islet cells depend on the adrenal nuclei, lumbar sympathetic nerves which are responsible for muscular activity depend on the $\mathrm{A} 5$ pontine nucleus. This latter branch of peripheral neural sympathetic activity is responsible for circulating noradrenaline plasma levels. ${ }^{31-34}$ It should also be noted that the adrenal medullary nuclei are responsible for adrenal gland secretion which depends on thoracic sympathetic preganglionic axons. ${ }^{26}$ These nuclei receive excitatory axons from other pontomedullary nuclei (acetylcholinergic, serotonergic, and glutamatergic), that are responsible for adrenal gland secretion, which is positively correlated with glucogenolysis and hyperglycemia. ${ }^{35}$ Special mention should be made about the excitatory drives which arise from the dorsal raphe 5-HT axons (highly associated with stress mechanisms and hyperglycemia), the abrogation of which with tianeptine (a serotonin uptake enhancer drug), is associated with reduction not only of serotonin but also of plasma adrenaline, glucagon, and glucose levels and, in addition, triggers increased insulin secretion. ${ }^{36-40}$ Thus, the hyperactivity of the $\mathrm{C} 1$ adrenal and dorsal raphe 5-HT axis should underlie the AN syndrome, which also includes raised plasma levels of both adrenaline and f5-HT. . $5,26,41^{2}$

The gastric paralyzation and hypotony seen in AN patients contrasts with the fast gastric emptying and hypertony present in subjects affected by hyperinsulinism and hypoglycemia. ${ }^{6,7}$ Radiologic investigation of these subjects always shows a hypertonic steer-horn stomach and an open pylorus which results in fast emptying. ${ }^{42}$ In addition, these patients also show increased plasma noradrenaline and decreased plasma adrenaline levels (very high noradrenaline:adrenaline plasma ratio), which is consistent with the predominance of neural over adrenal sympathetic peripheral branch. ${ }^{6}$

The understanding of the above-mentioned pathophysiologic mechanisms enables adequate neuropharmacologic therapy for both disorders. Whereas patients affected by hyperinsulinism and hypoglycemia can be successfully treated with drugs that minimize neural sympathetic activity, ${ }^{7}$ abrogation of the adrenal sympathetic branch by drugs which minimize the $\mathrm{C} 1$ adrenal medullary and dorsal raphe (5-HT) axis, eg, buspirone, ${ }^{41}$ amantadine, ${ }^{43,44}$ and/or tianeptine, ${ }^{36,37,45}$ would be able to reverse clinical and radiologic symptoms in $\mathrm{AN}$ patients. ${ }^{26}$

At the peripheral level, AN patients showed raised levels of f5-HT and decreased levels of p5-HT. This is consistent with the increased platelet aggregation known to be triggered by overflow of adrenaline. ${ }^{46}$ Plasma f5-HT released from platelets inhibits insulin release from beta cells. ${ }^{47-50} \mathrm{In}$ addition, plasma f5-HT, but not p5-HT excites the area postrema medullary nucleus (located outside the blood-brain barrier), 
which is crowded with $5-\mathrm{HT}_{3}$ excitatory receptors (Bezold Harish reflex). ${ }^{51,52}$ Excitation of this mechanism provokes vomiting that is suppressed by ondansetron (a 5- $\mathrm{HT}_{3}$ antagonist). The area postrema is the only 5-HT medullary nucleus which sends excitatory axons to the adrenal nuclei. ${ }^{53,54}$ Thus, these central and peripheral serotonergic mechanisms would be also annulled by amantadine. Finally, the $\mathrm{C} 1$ adrenal nuclei also receive glutamatergic excitatory drive from the hypothalamic area, ${ }^{55}$ that may be intercepted at this level by the drug, which explains its therapeutic effects based on the minimization of adrenal sympathetic hyperactivity. ${ }^{7,26,43}$ Our findings fit well with the decreased affinity of platelet alpha ${ }_{2}$ receptors and an adrenaline inhibitory effect as demonstrated by Heufelder et al. ${ }^{56}$

\section{Disclosure}

The authors report no conflicts of interest in this work.

\section{References}

1. Pirke KM, Ploog D. Psychobiology of anorexia nervosa. In: Wurtman RJ, Wurtman JJ, editors. Nutrition and the Brain. Vol 7. New York: Raven Press; 1986.

2. Stacher G, Peeters TL, Bergmann H, et al. Erythromycin effects on gastric emptying, antral motility and plasma motilin and pancreatic polypeptide concentrations in anorexia nervosa. Gut. 1993;34:166-172.

3. Lechin F, van der Dijs B, Orozco B, et al. Plasma neurotransmitters, blood pressure and heart rate during supine-resting, orthostasis and moderate exercise conditions in major depressed patients. Biol Psychiatry. 1995;38:166-173.

4. Lechin F, van der Dijs B, Jackubowicz D, et al. Role of stress in the exacerbation of chronic illness. Effects of clonidine administration on blood pressure, norepinephrine, cortisol, growth hormone and prolactin plasma levels. Psychoneuroendocrinology. 1987;12:117-129.

5. Burchfield SR. The stress response: A new perspective. Review. Psychosom Med. 1979;41:661-672.

6. Lechin F, van der Dijs B. Central nervous system (CNS) circuitry involved in the hyperinsulinism syndrome. Neuroendocrinology. 2006; $84: 222-234$.

7. Lechin F, van der Dijs B, Lechin A, et al. Doxepin therapy for postprandial symptomatic hypoglycemic patients neurochemical, hormonal and metabolic disturbances. Clin Sci. 1991;80:373-384.

8. Christensen NJ. Acute effects of insulin on cardiovascular function and noradrenaline uptake and release. Review. Diabetologia. 1983;25: 377-381.

9. Lechin F, van der Dijs B, Lechin M, et al. Effects of an oral glucose load on plasma neurotransmitters in humans: Involvement of REM sleep? Neuropsychobiology. 1992;26:4-11.

10. Elenkov IJ, Wilder RL, Chrousos GP, Vizi EZ. The sympathetic nerve - an integrative interface between two supersystems: The brain and the immune system. Pharmacol Rev. 2000;52:595-638.

11. Maiorov DN, Wilton ER, Badoer E, Petrie D, Head GA, Malpas SC. Sympathetic response to stimulation of the pontine A5 region in conscious rabbits. Brain Res. 1999;815:227-236.

12. Byrum CE, Guyenet PG. Afferent and efferent connections of the A5 noradrenergic cell group in the rat. J Comp Neurol. 1987;261: 529-542.

13. Dampney RA. Functional organization of central pathways regulating the cardiovascular system. Physiol Rev. 1994;74:323-364.
14. Lechin F, van der Dijs B, Jakubowicz D, et al. Effects of clonidine on blood pressure, noradrenaline, cortisol, growth hormone, and prolactin plasma levels in high and low intestinal tone in depressed patients. Neuroendocrinology. 1985;41:156-162.

15. McAuley MA, Macrae IM, Reid JL. The cardiovascular actions of clonidine and neuropeptide-Y in the ventrolateral medulla of the rat. Br J Pharmacol. 1989;97:1067-1074.

16. Li YW, Wesselingh SL, Blessing WW. Projections from rabbit caudal medulla to $\mathrm{C} 1$ and $\mathrm{A} 5$ sympathetic premotor neurons, demonstrated with phaseolus leucoagglutinin and herpes simplex virus. J Comp Neurol. 1992;317:379-395.

17. Reis DJ, Ruggiero DA, Morrison SF. The C1 area of the rostralventrolateral medulla oblongata. A critical brainstem region for control of resting and reflex integration of arterial pressure. Review. Am J Hypertens. 1989;2:S363-74.

18. Chan CK, Burke SL, Head GA. Contribution of imidazoline receptors and alpha2-adrenoceptors in the rostral ventrolateral medulla to sympathetic baroreflex inhibition by systemic rilmenidine. J Hypertens. 2007;25:147-155.

19. Chan CK, Burke SL, Zhu H, Piletz JE, Head GA. Imidazoline receptors associated with noradrenergic terminals in the rostral ventrolateral medulla mediate the hypotensive responses of moxonidine but not clonidine. Neuroscience. 2005;132:991-1007.

20. Kozaeva LP, Korobov NV, Medvedev OS. The role of alpha2adrenergic and I1-imidazoline receptors in the effects of clonidine and moxonidine on isolated large intestine of mice. Eksp Klin Farmakol. 2005;68:36-38.

21. Kino Y, Tanabe M, Honda M, Ono H. Involvement of supraspinal imidazoline receptors and descending monoaminergic pathways in tizanidine-induced inhibition of rat spinal reflexes. J Pharmacol Sci. 2005;99:52-60.

22. Morgan NG. Imidazoline receptors: New targets for antihyperglycaemic drugs. Expert Opin Investig Drugs. 1999;8:575-584.

23. van Zwieten PA. Antihypertensive drugs interacting with central imidazoline (I1)-receptors. Expert Opin Investig Drugs. 1998;7:1781-1793.

24. Lechin F, van der Dijs B. Central nervous system plus autonomic nervous system disorders responsible for the gastrointestinal and pancreatobiliary diseases. Review. Dig Dis Sci. 2009;54:458-470.

25. Lechin F, van der Dijs B. Central nervous system circuitries underlying two types of peripheral autonomic nervous system disorders. Open Neurosci J. 2008;2:41-50.

26. Lechin F, van der Dijs B. Crosstalk between the autonomic nervous system and the central nervous system: Mechanistic and therapeutic considerations for neuronal, immune, vascular, and somatic based diseases. In: Maiese K, editor. Neurovascular Medicine: Pursuing Cellular Longevity for Healthy Aging. New York, NY: Oxford University Press; 2009.

27. Fisher SJ, Brüning JC, Lannon S, Kahn CR. Insulin signaling in the central nervous system is critical for the normal sympathoadrenal response to hypoglycemia. Diabetes. 2005;54: 1447-1451.

28. Abdelmelek H, Fechtali T, Filali-Zegzouti Y, et al. Responsiveness of plasma catecholamines to intracerebroventricular injection of glucagon in Muscovy ducklings. J Neural Transm. 2001;108:793-801.

29. Cryer PE. Glucagon and hyperglycaemia in diabetes. Clin Sci (Lond). 2008;114:589-590.

30. Pirke KM, Eckert M, Ofers B, et al. Plasma norepinephrine response to exercise in bulimia, anorexia nervosa, and controls. Biol Psychiatry. 1989;25(6):799-802.

31. Strack AM, Sawyer WB, Platt KB, Loewy AD. CNS cell groups regulating the sympathetic outflow to adrenal gland as revealed by transneuronal cell body labeling with pseudorabies virus. Brain Res. 1989;491:274-296.

32. Strack AM, Sawyer WB, Hughes JH, Platt KB, Loewy AD. A general pattern of CNS innervation of the sympathetic outflow demonstrated by transneuronal pseudorabies viral infections. Brain Res. 1989;491:156-162. 
33. Strack AM, Loewy AD. Pseudorabies virus: A highly specific transneuronal cell body marker in the sympathetic nervous system. J Neurosci. 1990;10:2139-2147.

34. Loewy AD, Franklin MF, Haxhiu MA. CNS monoamine cell groups projecting to pancreatic vagal motor neurons: A transneuronal labeling study using pseudorabies virus. Brain Res. 1994;638:248-260.

35. Gerendai I, Halász B. Central nervous system structures connected with the endocrine glands. Findings obtained with the viral transneuronal tracing technique. Exp Clin Endocrinol Diabetes. 2000;108:389-395.

36. Lechin F, van der Dijs B, Hernandez G, Orozco B, Rodriguez S, Baez S Acute effects of tianeptine on circulating neurotransmitters and cardiovascular parameters. Prog Neuropsychopharmacol Biol Psychiatry. 2006;30:214-222.

37. Lechin F, van der Dijs B, Pardey-Maldonado B, Baez S, Lechin ME. Tianeptine enhances insulin secretion throughout the oral glucose tolerance test. J Appl Res. 2009;3:76-87.

38. Lechin F, van der Dijs B, Hernandez-Adrian G. Dorsal Raphe (DR) vs Median Raphe (MR) serotonergic antagonism. Anatomical, physiological, behavioral, neuroendocrinological, neuropharmacological and clinical evidences: Relevance for neuropharmacological therapy. Prog Neuropsychopharmacol Biol Psychiatry. 2006;30:565-585.

39. Peyron C, Luppi PH, Fort P, Rampon C, Jouvet M. Lower brainstem catecholamine afferents to the rat dorsal raphe nucleus. J Comp Neurol. 1996;364:402-413.

40. Ohliger-Frerking P, Horowitz JM, Horwitz BA. Enhanced adrenergic excitation of serotonergic dorsal raphe neurons in genetically obese rats. Neurosci Lett. 2002;332:107-110.

41. Lechin F, van der Dijs B, Jara H, et al. Effects of buspirone on plasma neurotransmitters in healthy subjects. J Neural Transm. 1998;105:561-573.

42. Lechin F, van der Dijs B, Rada I, et al. Plasma neurotransmitters and cortisol in duodenal ulcer patients: Role of stress. Dig Dis Sci. 1990;35:1313-1319.

43. Lechin F, van der Dijs B, Pardey-Maldonado B, Rivera JE, Baez S, Lechin ME. Effects of amantadine on circulating neurotransmitters in healthy subjects. J Neural Transm. 2010;117:293-299.

44. Lechin F, van der Dijs B, Pardey-Maldonado B, Rivera JE, Lechin ME, Baez S. Amantadine reduces glucagon and enhances insulin secretion throughout the oral glucose tolerance: Central plus peripheral nervous system mechanisms. Diabetes Metab Syndr Obes. 2009;2:203-213.
45. Lechin F. Central and plasma 5-HT, vagal tone and airways. Trends Pharmacol Sci. 2000;21:425.

46. Luck P, Mikhailidis DP, Dashwood MR, et al. Platelet hyperaggregability and increased alpha-adrenoceptor density in anorexia nervosa. J Clin Endocrinol Metab. 1983;57(5):911-914.

47. Lechin F, van der Dijs B, Lechin M, et al. Plasma neurotransmitters throughout an oral glucose tolerance test in essential hypertension. Clin Exp Hypertens. 1993;15(1):209-240.

48. Lechin F, van der Dijs B. Intestinal pharmacomanometry and glucose tolerance: Evidence for two antagonistic dopaminergic mechanisms in the human. Biol Psychiatry. 1981;16(10):969-986.

49. Lechin F, van der Dijs B. Enterohormonas, insulina y glucagon. Acta Gastroenter Latinoamer. 1978;8:27-39. Spanish.

50. Lechin F, Coll-Garcia E, van der Dijs B, Peña F, Bentolila A, Rivas C. The effect of serotonin (5-HT) on insulin secretion. Acta Physiol Latinoamer. 1975;25:339-346. Spanish.

51. Reynolds DJM, Leslie RA, Grahame-Smith DG, Harvey JM Localization of 5-HT3 receptor binding sites in human dorsal vagal complex. Eur J Pharmacol. 1989;174:127-130

52. Wilson CG, Bonham AC. Area postrema excites and inhibits sympathetic-related neurons in rostral ventrolateral medulla in rabbit. Am J Physiol. 1994;266(3 Pt 2):H1075-H1086.

53. Gauthier P, Reader TA. Adrenomedullary secretory response to midbrain stimulation in rat: Effects of depletion of brain catecholamines or serotonin. Can J Physiol Pharmacol. 1982;60:1464-1474.

54. Urbanski RW, Sapru HN. Evidence for a sympathoexcitatory pathway from the nucleus tractus solitarii to the ventrolateral medullary pressor area. J Auton Nerv Syst. 1988;23:161-174.

55. van Bockstaele EJ, Pieribone VA, Aston-Jones G. Diverse afferents converge on the nucleus paragigantocellularis in the rat ventrolateral medulla: Retrograde and anterograde tracing studies. J Comp Neurol. 1989;290:561-584.

56. Heufelder A, Warnhoff M, Pirke KM. Platelet alpha 2-adrenoceptor and adenylate cyclase in patients with anorexia nervosa and bulimia. J Clin Endocrinol Metab. 1985;61:1053-1060.

\section{Publish your work in this journal}

Diabetes, Metabolic Syndrome and Obesity: Targets and Therapy is an international, peer-reviewed open-access journal committed to the rapid publication of the latest laboratory and clinical findings in the fields of diabetes, metabolic syndrome and obesity research. Original research, review, case reports, hypothesis formation, expert opinion and commentaries are all considered for publication. The manuscript management system is completely online and includes a very quick and fair peer-review system, which is all easy to use. Visit http://www.dovepress.com/testimonials.php to read real quotes from published authors. 